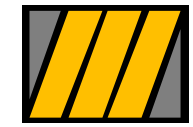

ESCUELA DE NEGOCIOS Universidad Torcuato Di Tella

\section{CIF}

Centro de Investigación en Finanzas

Documento de Trabajo 01/2003

\title{
Endogenous Deposit Dollarization
}

Eduardo Levy Yeyati

Universidad Torcuato Di Tella

and

Christian Broda

FRBNY
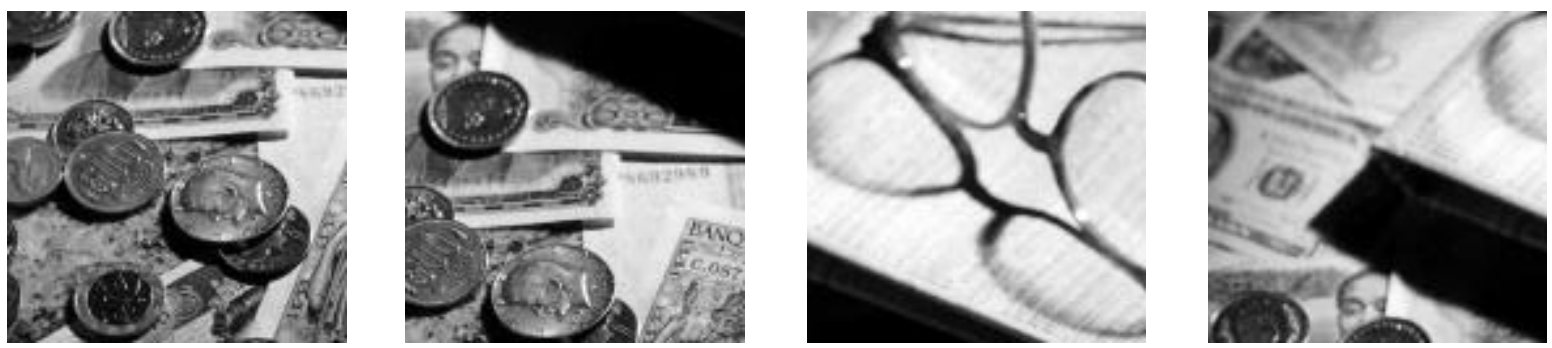

Miñones 2177, C1428ATG Buenos Aires • Tel: 4784.0080 interno 181 y $4787.9394 \bullet$ Web site: www.utdt.edu/departamentos/empresarial/cif/cif.htm 


\title{
Endogenous Deposit Dollarization
}

\author{
Christian Broda and Eduardo Levy Yeyati
}

February 2003

\begin{abstract}
This paper explores sources of deposit dollarization unrelated to standard moral hazard arguments. We develop a model in which banks choose the optimal currency composition of their liabilities. We argue that the equal treatment of peso and dollar claims in the event of bank default can induce banks to attract dollar deposits above the socially desirable level. The distortion arises because dollar deposits are the only source of default risk in the model, but dollar depositors share the burden of the default with peso depositors. The incentive to dollarize is reinforced by common banking system safety nets such as deposit and bank insurance. Our findings suggest that regulators in bi-currency economies would potentially benefit by departing from the currency-blind benchmark and di.erentiating among currencies in a way that prevents undesirable currency mismatches.
\end{abstract}

JEL classification: G11, G21, F31

Broda: Research Department, Federal Reserve Bank of New York, New York, N.Y. 10045 (e-mail: christian.broda@ny.frb.org); Levy Yeyati: Business School, Universidad Di Tella, Buenos Aires, Argentina (e-mail: ely@utdt.edu). We are grateful to Miguel Broda, Rudi Dornbusch, Augusto de la Torre, and Roberto Rigobon for their helpful comments. We also benefited from suggestions of seminar participants at MIT, the Federal Reserve Bank of New York, Universidad Di Tella, and LACEA (2000). All remaining errors are our own. The views expressed in this paper are those of the authors and are not necessarily reflective of views at the Federal Reserve Bank of New York or the Federal Reserve System. 


\section{Introduction}

In many emerging markets domestic financial intermediation is carried out in two (or more) currencies. Since the dollar is generally the main foreign-currency of choice, this phenomenon has been named financial dollarization in the literature. Financial dollarization can take several forms, including foreign borrowing (domestic banks or local firms borrowing directly from abroad as in the case of Thailand and Indonesia in the 90s or Chile and Argentina in the early 80s) and deposit dollarization (domestic asset holders saving locally in foreign-currency deposits as in Turkey and Argentina in the 90s).

While the issue of foreign borrowing has received attention in the literature (see Diaz Alejandro (1985), Burnside et al. (2001b) and Caballero and Krishnamurthy (2002))1, deposit dollarization has been almost completely neglected, ${ }^{2}$ despite the evidence suggesting its empirical relevance in many emerging markets (see Baliño et al (1999)). In principle there are reasons why domestic savers may prefer to save in dollars rather than in domestic currency (henceforth, for simplicity, the peso). Thomas (1985) and Ize and Levy Yeyati (2002) explain the process of dollarization as an optimal portfolio choice by depositors. These models, however, ignore important aspects of the financial intermediation process such as the balance sheet imbalances caused by currency mismatches. In this paper we abstract from the depositor's decision and focus on whether it may be in the best interest of banks in emerging markets to attract dollar deposits. By acquiring dollar deposits, banks face a trade-off between the lower dollar rates and an increase in default risk associated with currency mismatch. ${ }^{3}$ We are interested in examining under what conditions the former effect dominates the latter and whether these conditions induce excessive dollarization by banks. We also address the implications for bank regulators in emerging markets.

\footnotetext{
${ }^{1}$ A number of papers have build upon the currency mismatch that arise in these models to generate currency crisis models. They include Aghion et al. (2000), Dooley (1997), McKinnon and Pill (1998), Corsetti, Roubini and Pesenti (1999) and Chang and Velasco (2000).

${ }^{2}$ With a few exceptions, the literature that tackled deposit dollarization has typically focused on currency substitution rather than asset substitution issues, despite the fact that the bulk of observed dollarization has ocurred in the savings component of broad money (interest bearing deposits) with little, if any, substitution of the domestic currency been as a means of payment.

${ }^{3}$ In the event of a sudden devaluation, the erosion of the dollar value of bank assets denominated in pesos impinges on the capacity to repay deposits of currency-imbalanced banks or, if banks' dollar position is limited by the regulator, of dollar-indebted firms. A similar trade-off appears in Caballero and Krishnamurthy (2002) in the context of foreign borrowing by firms.
} 
In our model, limited-liability banks choose the currency composition of their liabilities. They collect peso and dollar deposits from risk-neutral depositors to finance domestic projects with known peso returns. ${ }^{4}$ Exchange rate risk is the sole source of uncertainty in the model. The presence of dollar deposits gives rise to a currency imbalance in the banks' balance sheet that implies that low exchange rate states (i.e., peso depreciations) are associated with bank insolvency. In this context, the treatment of deposits in the case of bank default is the key to distinguishing between the banks' and the central planner's valuation of dollar deposits. ${ }^{5}$

We show that an equal treatment of peso and dollar deposits in the event of a bank liquidation, creates an incentive for banks to dollarize. ${ }^{6}$ For any given pair of deposit rates, the cost for banks of dollar deposits relative to peso deposits is larger the lower is the exchange rate. But it is in those states when the exchange rate is low that a bank is likely to default, and therefore not internalize the cost differential between deposits. Thus, the peso-dollar spread priced by risk neutral depositors will exceed the effective relative cost of dollar liabilities for the bank, inducing a preference for dollar funding. This mispricing of exchange rate risk by banks leads to an excessive level of dollarization.

Our main result differs from most of the foreign borrowing literature cited above in that dollar debts are not driven by the presence of government or private guarantees. In Burnside et al (2001b) and Dooley (1997), the free insurance provided by the government induces banks to borrow from abroad. On the other hand, in our model all that is needed is a currency-blind liquidation policy, that is, one that distributes the residual value of the failed bank among depositors according to the value of their claims. ${ }^{7}$ Moreover, in the free insurance models, the burden of the default is transferred to the insurer while in our model such burden falls onto the peso depositors. In Caballero and Krishnamurthy (2002), the incentive for firms to

\footnotetext{
${ }^{4}$ While we assume that project returns are entirely denominated in pesos, the results can be readily extended to include the case in which a fraction of borrowers have foreign-denominated income.

${ }^{5}$ Methodologically, our paper is closer to Thomas (1985) and Blum (1999), differing from the tradition of Kareken and Wallace (1978) in that, in our case, the banks' decision is related to the liability (rathet than the asset) side of the banks' balance sheet.

${ }^{6}$ Note that, in the event of default, depositors still recover a fraction of their assets through the distribution of the residual value of the failed bank's portfolio.

${ }^{7}$ The result extends to liquidation policies that, while not currency-blind, do not strongly discriminate against dollar depositors. This treatment is not unusual in practice. For instance, bankruptcy laws do not adjust creditors' assets for their currency of denomination. For a summary of how prudential regulation deals with foreign exchange risk, see Abrams and Beato (1998).
} 
issue excessive dollar debt arises from the interaction between the value of dollar collateral and the presence of financial constraints. As in Caballero and Krishnamurthy, our model also presents the advantage of not having to rely on an insurer with deep pockets. In our model, by contrast, the incentive to dollarize closely depends on the interaction between default risk and currency risk. We believe that this interaction is a crucial feature of emerging markets economies.

The introduction of deposit or bank insurance reinforces the main effect of the model. For instance, a deposit insurance that does not discriminate between currencies, by increasing the recovery value of deposits in both currencies in the event of default, widens the wedge between the peso-dollar spread and the effective funding costs faced by banks, reinforcing the previous effect. As in the case of no deposit insurance, the incentive to dollarize arises from the mispricing of exchange rate risk rather than from the standard moral hazard consequences of insurance. ${ }^{8}$

In the model, the standard consequences of free insurance are present as an additional force inducing deposit dollarization. For instance, a lender of last resort that provides insurance to banks irrespective of their level of dollarization reduces the cost of risk taking, which in the context of the model implies a higher equilibrium share of dollar deposits. Banks are willing to increase the level of dollar funding as they transfer part of the exposure to the provider of the insurance services. This result is analogous to that in Kareken and Wallace (1978) and Burnside et al (2001b) who find that, in the presence of government guarantees, it is optimal for limited liability banks to hold as risky a portfolio as permissable to maximize the value of the guarantee. In our model, however, full dollarization is mitigated because of an additional intertemporal value effect that reduces the incentive to dollarize as risk increases. ${ }^{9}$ A different form of bank insurance comes from the (explicit or implicit) commitment of the Central Bank to defend the price of the domestic currency. As opposed to Dooley (1997) we find that a goverment's promise to defend the exchange rate has ambiguos effects on the

\footnotetext{
${ }^{8}$ The standard moral hazard effect is associated with Grossman and Hart (1992). They stress that the possibility of a bailout reduces the incentive to exert effort and encourages managerial shirking and risk taking. See Freixas and Rochet (1997) Ch.9 for applications to bank insurance.

${ }^{9}$ Blum (1999) describes a similar effect when assessing the effect of capital adequacy rules in the banks' riskiness. Cordella and Levy Yeyati (1999) discuss extensively this value effect when examining the impact of bank insurance on banks' risk appetite.
} 
equilibrium dollarization.

In our model, the mispricing of exchange rate risk arises because of a negative externality of having dollar deposits. Dollar-deposits are the only source of default risk in the model but the burden of the default is shared across all deposits. Standard banking practices (such as deposit insurance or central bank assistance) that do not discriminate between currencies reinforce this externality. For instance, central banks are not known to base their assistance to particular banks on the currency composition of their portfolios above and beyond what is required by prudential regulations. Moreover, currency-blind deposit insurance is the rule rather than the exception. In her extensive survey, Garcia (1999) finds that less than twenty out of seventy-two countries with bi-currency financial systems discriminate against foreign-currency deposits by excluding them from the insurance coverage. Demirguc-Kunt and Detragiache (2000) find evidence that deposit insurance which includes coverage for foreign currency increases the probability of a bank run. ${ }^{10}$ Our investigation points to the benefits of extending banking practices and regulations to include a distinct role for deposits denominated in different currencies.

Finally, the model also highlights an interesting empirical implication, namely, that the peso-dollar interest rate spread typically used to measure currency risk generally underestimates devaluation expectations, the more so the larger the deposit dollarization ratio is. This implication is in line with evidence in Schmukler and Serven (2002) that shows that, in highly dollarized Argentina and Hong Kong, forward discounts exceed the currency premium implicit in bank interest rates, particularly during currency runs when deposit dollarization tends to peak.

The paper proceeds as follows. In section 2 we present the basic model and describe the centralized and decentralized equilibria with no deposit or bank insurance. In section 3 we analyze, in turn, how insurance affects the degree of deposit dollarization in the economy. In section 4 we discuss the empirical implications of the results for the measurement of currency

\footnotetext{
${ }^{10}$ They suggest that, just as in the case of general deposit insurance, foreign-currency coverage may stimulate banks' risk-taking behaviour due to standard moral hazard considerations. We provide a different explanation for this link between insurance and the propensity to banking crises: the extension of insurance to foreign currency bank liabilities endogenously drives up dollarization, which, in turn, leaves banks more exposed to currency risk. Thus, even in the absence of market discipline, dollar deposit insurance contributes to financial fragility.
} 
risk based on market interest rates. In section 5 we discuss the empirical and normative implications of the model and conclude.

\section{The Model}

This section presents a simple dynamic framework to analyze the determinants of the currency composition of banks' deposit portfolio in a bi-currency banking system. We examine how banks, depositors, and the central bank (alternatively, the bank liquidation agency) interact in an economy with exchange rate risk as the only source of risk.

Consider the case of limited liability banks endowed with an investment technology that uses 1 dollar (or $1 / e$ pesos, where $e$ is the dollar/peso exchange rate) to produce $R$ pesos at the end of the period. Normalizing the current exchange rate $e_{0}$ to one, assume that the end-of-period exchange rate is distributed according to $f(e)$ with support $[0, \infty], f(0)=0$, and mean $e^{m}$. We can think of $e$ as driven by exogenous shocks, with low values (large depreciations) corresponding to bad states of nature. Finally, for simplicity, assume that the distribution of end-of-period exchange rate rate changes is identical in each period (i.e., does not depend on history).

The assumption that investment returns are denominated in pesos captures the fact that, whenever the degree of financial dollarization exceeds the fraction of the real economy effectively dollarized, there is a currency mismatch somewhere in the economy. In the event of a sudden devaluation, the erosion of the dollar value of peso-denominated assets impinges on the debtors' capacity to repay, either of dollar-indebted firms or of currency imbalanced banks. For simplicity, we model this currency mismatch in the banks' balance sheet. ${ }^{11}$

Each bank has to decide the optimal currency composition of its liability portfolio. Given the recursive nature of the problem, and expressing values in dollar terms, we can express

\footnotetext{
${ }^{11}$ The model, however, is quite general. It could be easily extended to the case in which banks are assumed to lend in the same currency due to limits on the currency position. As the recovery value of their loans will still be limited by the peso income of the borrower, the currency mismatch is simply shifted to the firms (i.e., replaced by exchange rate-related credit risk), to the same result. Also, substituting firms for banks, the model could be readily applied to the case of direct financing.
} 
the bank's objective function as:

$$
\begin{aligned}
V & =\max _{\lambda} \sum_{i=0}^{\infty} \rho^{i} P\left(\lambda_{i}\right) \pi\left(\lambda_{i}\right)=\max _{\lambda} \frac{\pi(\lambda)}{1-\rho P(\lambda)}, \\
\text { with } \pi(\lambda) & \left.=\int_{0}^{\infty} \max \left[0, e\left(R-(1-\lambda) r_{p}\right)-\lambda r_{d}\right)\right] f(e) d e
\end{aligned}
$$

where $\lambda$ is the share of dollar deposits, $r_{p}$ and $r_{d}$ are the (gross) interest rates of peso and dollar deposits, respectively, and $P(\lambda)$ is the probability that the bank does not default. The profit function can be restated as:

$$
\pi=\int_{e_{c}(\lambda)}^{\infty}\left[e\left(R-(1-\lambda) r_{p}\right)-\lambda r_{d}\right] f(e) d e=P(\lambda)\left[\bar{e}(\lambda)\left(R-(1-\lambda) r_{p}\right)-\lambda r_{d}\right]
$$

where $e_{c}$ denotes the critical value of end-of period exchange rate below which bank liabilities exceed bank assets, and $\bar{e}(\lambda)$ is the average exchange rate conditional on the bank's not defaulting, that is, ${ }^{12}$

$$
\begin{aligned}
e_{c}(\lambda) & \equiv \frac{\lambda r_{d}}{R-(1-\lambda) r_{p}} \\
\bar{e}(\lambda) & =\frac{\int_{e_{c}(\lambda)}^{\infty} e f(e) d e}{P(\lambda)}
\end{aligned}
$$

In the absence of insurance, when a bank defaults it is liquidated at a discount $0<\theta \leq 1$ and the residual value of the liquidated bank, $\theta R$, is distributed among depositors (in a way to be discussed below). Finally, we assume that $R$ is such that, for any liquidation $\operatorname{cost} \theta$, it is efficient to have a positive level of investment, that is,

$$
P \bar{e} R>r_{f}
$$

For future reference, note that $\bar{e}>e^{m}>e_{c}$.

To make our argument as plain as possible, we simplify the depositor's portfolio decision problem. We assume that risk-neutral depositors can either invest in dollar deposits, peso

\footnotetext{
${ }^{12}$ For future reference note that $e_{c}^{\prime}>0$ implies that $P^{\prime}<0$.
} 
deposits or an outside risk-free asset with return $r_{f} \geqslant 1 .{ }^{13}$ This implies that depositors are indifferent to the currency denomination of the deposits as long as:

$$
r_{p}^{e}=\int_{0}^{\infty} e \widetilde{r}_{p} f(e) d e=r_{f}=\int_{0}^{\infty} \widetilde{r}_{d} f(e) d e=r_{d}^{e}
$$

where $\widetilde{r}_{i}$ equals $r_{i}$ if the bank does not default, and whatever return they receive from the central bank in case of default. Depositors do not observe the bank's dollarization share. Thus, we implicitly assume that the bank cannot commit to a posted interest rate (which would reveal the bank's portfolio choice), reflecting the fact that rates are customarily negotiated with each client on a personal basis.

\section{A. Centralized equilibrium}

As a useful benchmark, we present the solution for the optimal dollarization share in a centralized equilibrium. A risk neutral central planner maximizes the expected return to investment minus expected funding and liquidation costs, taking into account the effect the composition of liabilities has on the deposits interest rates. Replacing (7) into (1), we then obtain: $:^{14}$

$$
\begin{aligned}
& V^{*}=\max _{\lambda} \sum_{i=0}^{\infty} \rho^{i}\left[\int_{0}^{\infty} e R f(e) d e-(1-\theta) \int_{0}^{e_{c}(\lambda)} e R f(e) d e-r_{f}\right] \\
= & \max _{\lambda} \frac{e^{m} R-(1-\theta) R([1-P(\lambda)] \underline{e}(\lambda))-r_{f}}{1-\rho} .
\end{aligned}
$$

where $\underline{e}(\lambda)=\frac{\int_{0}^{e_{c}(\lambda)} e f(e) d e}{1-P(\lambda)}$.

Proposition 1. When $\theta<1$, the optimal share of dollar deposits is $\lambda^{*}=0$. When $\theta=1$ the central planner is indifferent about the composition of funding.

Proof. The result follows immediately from $e_{c}^{\prime}>0$.

In other words, in the presence of liquidation costs it is optimal that banks fully hedge exchange rate risk by demanding no dollar deposits. ${ }^{15}$ The intuition is straightforward: since

\footnotetext{
${ }^{13}$ For a discussion of the role of risk aversion in the depositors' portfolio problem, see Ize and Levy Yeyati (2001).

${ }^{14}$ It follows from condition (6) that $R$ is big enough for investment to be optimal.

${ }^{15}$ This proposition is analogous to the results in Kareken and Wallace (1978), where they show that with no
} 
the central planner internalizes the effect $\lambda$ has on $r_{p}(\lambda)$ and $r_{d}(\lambda)$, dollarization does not entail any gain in terms of lower funding costs, while it does generate a potential risk of default, with the associated losses due to liquidation costs. Without these costs, the ModiglianiMiller principle applies (the central planner is indifferent regarding the denomination of bank funding).

\section{B. Decentralized equilibrium}

In the absence of a deposit or bank insurance scheme, interest rates depend crucially on the way the bank's assets are distributed among depositors in the event of default (what we henceforth refer to as the "liquidation policy"). Any liquidation policy can be generally characterized by the recovery ratios $\delta_{i}(\lambda, e)$ applicable to deposits in currency $i$, defined as the share of the deposit certificate that is repaid at maturity. The fact that the (dollar) residual value of the bank, $e \theta R$, is completely distributed among depositors implies that these ratios have to satisfy the following aggregate constraint:

$$
(1-\lambda) e \delta_{p}(\lambda, e) r_{p}+\lambda \delta_{d}(\lambda, e) r_{d}=e \theta R
$$

Denoting the expected recovery value (again, expressed in dollars) of a unit currency $i$ denominated deposit in the event of a default by $S_{i}(\lambda, e)$, where $i=p, d$, we obtain: ${ }^{16}$

$$
\begin{aligned}
S_{d} & =\int_{0}^{e_{c}} \delta_{d}(\lambda, e) f(e) d e \\
S_{p} & =\int_{0}^{e_{c}} e \delta_{p}(\lambda, e) f(e) d e .
\end{aligned}
$$

In turn, using (5), depositors' expected returns must satisfy the following arbitrage condition:

$$
r_{p}^{e}=r_{p}\left[P(\lambda) \bar{e}+S_{p}(\lambda)\right]=r_{d}\left[P(\lambda)+S_{d}(\lambda)\right]=r_{d}^{e}=r_{f}
$$

\footnotetext{
government guarantees (in their case, no deposit insurance) the presence of bankruptcy costs induce banks to avoid bankruptcy states, which implies fully hedging against the existing risk. Our Proposition 1 also closely resembles Proposition 4.1 in Burnside et al. (1999).

${ }^{16}$ Note that the recovery ratio for peso and dollar deposits may vary with the exchange rate. Therefore, the expected recovery value for each type of deposit has to be expressed in a common currency.
} 
Finally, from (12) it follows that the peso-dollar spread is given by:

$$
\frac{r_{p}}{r_{d}}=\frac{1}{\bar{e}} \times\left(1+\frac{S_{d} r_{d}-S_{p} r_{p}}{r_{d} P(\lambda)}\right)
$$

For future reference, $s(\lambda) \equiv S_{d} r_{d}-S_{p} r_{p}$ is a measure of the expected cross-transfer from peso deposits to dollar deposits in the event of a default. Note that, if the liquidation policy implies that the recovery value of dollar deposits is higher than the recovery value of peso deposits (expressed in dollars), then there is a transfer of resources from peso to dollar depositors that have to be compensated by a higher expected return of peso deposits in non-default states. More precisely, the higher the cross-transfer, the higher the peso-dollar spread demanded by risk neutral depositors. The general link between liquidation policies and the cross-transfer is summarized in the following remark:

Remark 1. $s\left(\lambda^{+}\right) \gtrless 0$ iff $S_{d} r_{d} \gtrless S_{p} r_{p}$ (where $\left.\lambda^{+} \epsilon(0,1]\right)$, and $s(0)=0$.

In particular, a currency-blind liquidation policy that grants equal treatment across deposits of different currencies (that is, $\delta_{p}=\delta_{d}$ ), by fully recognizing the exchange rate insurance of dollar deposits in the event of default, induces a widening of the peso-dollar spread. More precisely, if

$$
\delta_{p}(\lambda, e)=\delta_{d}(\lambda, e)=\delta(\lambda, e)=\frac{e \theta R}{e(1-\lambda) r_{p}+\lambda r_{d}}
$$

then, using $r_{d}-r_{p} e_{c}>0,{ }^{17}$ we obtain

$$
s(\lambda)=\int_{0}^{e_{c}} \delta(\lambda, e)\left(r_{d}-r_{p} e\right) f(e) d e>0
$$

On the other extreme, a liquidation policy that completely ignores valuation gains (as, e.g., in the case of a compulsory conversion of dollar deposits to the local currency at the rate $\left.e_{0}\right)$ would entail $\delta_{d}(\lambda, e)=e \delta_{p}(\lambda, e)$. As a result, $S_{p}=S_{d}=\frac{\theta R}{(1-\lambda) r_{p}+\lambda r_{d}}=S, s(\lambda)=$

\footnotetext{
${ }^{17}$ From (12), and using $e_{c}<e^{m}$ :

$$
\frac{r_{p}}{r_{d}}=\frac{\int_{e_{c}}^{\infty} f(e) d e+\int_{0}^{e_{c}} \delta(\lambda, e) f(e) d e}{\int_{e_{c}}^{\infty} e f(e) d e+\int_{0}^{e_{c}} \delta(\lambda, e) e f(e) d e}=\frac{1}{e^{m}} \times \frac{1-\int_{0}^{e_{c}}(1-\delta(\lambda, e)) f(e) d e}{1-\int_{0}^{e_{c}}(1-\delta(\lambda, e)) \frac{e}{e^{m}} f(e) d e}<\frac{1}{e^{m}}<\frac{1}{e^{c}} .
$$
}


$S\left(r_{d}-r_{p}\right)<0$, and peso depositors are subsidized by dollar depositors, as the latter are punished in the event of the default.

We are now ready to analyze the banks' equilibrium allocation. A Nash equilibrium is defined as the triplet $\left(\lambda^{D}, r_{p}, r_{d}\right)$ such that the bank maximizes (1), condition (12) holds, and $\lambda^{D}=\lambda^{e}$. Differentiating (1) with respect to the dollarization ratio $\lambda$, we obtain the following first order condition:

$$
F O C \equiv \frac{\partial V}{\partial \lambda}=\frac{1}{1-\rho P(\lambda)}\left(\pi^{\prime}+\rho P^{\prime} V\right)
$$

In turn, using

$$
\bar{e}^{\prime}=-\frac{e_{c}^{\prime}(\lambda) f\left(e_{c}\right) e_{c}}{P}-\frac{P^{\prime} \bar{e}}{P}=\frac{P^{\prime}}{P}\left(e_{c}-\bar{e}\right)
$$

and (13), we get:

$$
\pi^{\prime}=P\left(\bar{e} r_{p}-r_{d}\right)=s(\lambda)
$$

and

$$
\pi^{\prime \prime}=P^{\prime}\left(e_{c} r_{p}-r_{d}\right) \geq 0
$$

From (16) and (17) it can be easily seen that:

i) If $s(\lambda)>0$, the solution to the static problem (maximization of current profits, equation (3)) is always at the corner $\lambda=1 .^{18}$

ii) There is an intertemporal effect that reduces the incentive to dollarize, as the bank's expected future value falls by the term $\rho P^{\prime} V$ when the share of dollar deposits (and the probability of default) increases.

It can be proven that, for a low discount factor $\rho$, the stimulus to dollarize prevails, as the following proposition formally states:

Proposition 2. For $\rho \leq \rho_{c} \equiv \frac{r_{f}}{e^{m} R}, s(\lambda)>0$ implies that any decentralized equilibrium $\lambda^{D}$ must satisfy $\lambda^{D}>\lambda^{*}=0$.

Proof. See appendix for proof

\footnotetext{
${ }^{18}$ The problem is convex, and $\pi^{\prime} \geq 0$ for all $\lambda$. This implies bang-bang solutions similar to those found in Suarez (1993). The model can be easily extended to include liquidity services of the domestic currency. While in this case the solution to the problem may be interior, our main result, namely that there is a positive link between $s$ and $\lambda$, still holds.
} 
The main intuition behind this proposition comes from the effect of the liquidation policy on the wedge between the effective funding costs in pesos and dollars for the bank relative to the market price of peso and dollar deposits. Since the bank only pays depositors in non-default states, the relative peso funding cost is given by $\frac{r_{p} \bar{e}}{r_{d}}$, where $\bar{e}$ is the average exchange rate for those states. When the liquidation policy entails no cross-transfer $(s=0)$, no additional premium is required by peso deposit holders in non-default states (from (13), $\left.r_{p} \bar{e}=r_{d}\right)$. Then, absent any cost benefit of dollar funding, the bank shies away from the dollar to avoid currency risk. ${ }^{19}$

As the cross-transfer increases, $s>0$, the expected recovery value for dollar relative to pesos deposits rises, and with it the peso-dollar spread demanded by depositors. This higher spread introduces a positive wedge between the effective funding cost of peso deposits relative to dollar deposits $\left(r_{p} \bar{e}-r_{d}>0\right)$. This cost advantage associated with dollar funding eventually dominates the disincentives arising from the intertemporal effect, inducing deposit dollarization.

Thus, in our simple setup, deposit dollarization is entirely accounted for by the crosstransfers implicit in the liquidation policy. Note, in particular, that there is no need for a government guarantee, in the form of deposit or bank insurance, for the result to hold. Simple recognition of the currency of denomination of the deposit contract is enough to generate the result.

While the argument is valid for a variety of different liquidation schemes, in what follows we restrict our attention to the realistic (and more tractable) benchmark of a currency-blind liquidation policy as described in (14).

\section{Insurance}

Previously, we showed how the loss sharing implicit in default events resulted in endogenous dollarization. In this section we introduce deposit and bank insurance to explore how each of these standard safety nets influences the incentives for endogenous dollarization. In the final

\footnotetext{
${ }^{19}$ In the absence of a cross-transfer $(s=0)$, the peso-dollar spread simply reflects exchange rate risk considerations, as default risk affects deposits in both currencies in the same way, and the spread correctly captures the relative cost of borrowing in different currencies for the bank.
} 
part of this section, we explore the consequences of an (anticipated) exchange rate defense as an alternative insurance mechanism against exchange rate shocks.

\section{A. Deposit insurance}

The framework of the previous section can be readily applied to analyze the effect of an (implicit or explicit) currency-blind deposit insurance scheme (DIS) on the equilibrium share of dollar deposits. For expositional purposes, in what follows we assume that the DIS is financed through lump-sum taxes. ${ }^{20}$

A partial insurance policy can be characterized by a coverage ratio $\delta^{D I S} \equiv \delta(\lambda, e ; k)=$ $\max \{\delta(\lambda, e), k\}$, where $k \in(0,1) .{ }^{21}$ In this case, $r_{d}-r_{p} e_{c}>0$ implies that

$$
s(\lambda)=\int_{0}^{e_{c}} \max \{\delta(\lambda, e), k\}\left(r_{d}-r_{p} e\right) f(e) d e>\int_{0}^{e_{c}} \delta(\lambda, e)\left(r_{d}-r_{p} e\right) f(e) d e>0,
$$

so that, using the same argument as Proposition 2, it can be shown that, for sufficiently low discount factors, zero deposit dollarization can never be achieved in equilibrium under deposit insurance. More formally, from (19) it follows that:

Proposition 3. For $\rho \leq \rho_{c} \equiv \frac{r_{f}}{e^{m} R}$, any decentralized equilibrium dollarization ratio under deposit insurance, $\lambda^{D I S}$, must satisfy $\lambda^{D I S}>\lambda^{*}=0$.

Proof. Along the lines of Proposition 2

Note that, as in Proposition 2, the result is driven by the effect the DIS has on the current relative pricing of deposits and not from the well-known moral hazard consequences of insurance. From the depositors' standpoint, the DIS enhances the insurance properties of the dollar by enlarging the fraction of dollar deposits that are protected against exchange rate risk for non-default states, increasing their attractivenes as a hedge against large devaluations and inducing peso depositors to demand a compensating premium that creates a wedge between the market spread and the effective relative costs to the bank. In passing, it is

\footnotetext{
${ }^{20}$ This case, which assumes that DIS outlays are financed ex-post through the government budget, broadly corresponds to cases of implicit insurance or flat-rate, underpriced DIS. The analysis can be easily generalized to other financing strategies as long as they do not discriminate across currencies.

${ }^{21}$ Note that $\delta^{D I S}=k$ would imply that, for some states of nature, $k<\delta(\lambda, e)$, so that depositors will be distributed less than the residual value of the bank with the difference accruing to the DIS agency, an arguably unrealistic situation.
} 
interesting to note that, whenever the cost of the DIS is sustained by the government, the scheme can be viewed as a tax on depositors in both currencies whereby proceeds are allocated disproportionally among dollar depositors. ${ }^{22}$

Less straightforward is the question of whether a DIS strengthens or weakens the incentive to dollarize. On the one hand, it follows directly from (19) that, for given interest rates, the DIS increases the cross-transfer $s(\lambda)$ and hence banks' incentives to dollarize their liabilities. Moreover, it is easy to verify that $\delta(\lambda, e)$ is increasing in $e$, so that the increase in the recovery value due to the DIS is larger for smaller values of $e$, enhancing its effect on $s(\lambda)$. However, the DIS increases the pool of resources to be distributed among depositors and, as a result, reduces interest rates. In turn, lower funding costs reduce the probability of default, detracting from the attractiveness of dollar deposits as well as increasing the strength of the intertemporal effect (as larger charter values reduces the banks' risk-taking propensity). Thus, whether the introduction of a DIS reduces or increases endogenous dollarization will generally depend on the parameters of the problem.

Again, the example of a full DIS helps to illustrate this intuition. First note that, under a full DIS, the peso-dollar spread should simply reflect the devaluation expectations, so that, for any expected dollarization ratio $\lambda^{e}$,

$$
\frac{r_{p}}{r_{d}}=\frac{1}{e^{m}}
$$

Then, the first (pro-dollarization) effect can be seen by comparing conditions (17) with and without deposit insurance. Using the fact that without deposit insurance ${ }^{23}$

\footnotetext{
${ }^{22}$ Note also that the result still holds when the DIS is funded through bank contributions (e.g., a tax on profits), as long as the insurance premium does not depend on risk (i.e., the currency of denomination). In this case, $V_{D I S}=(1-\tau) \max _{\lambda} \frac{\pi(\lambda)}{1-\delta P(\lambda)}$ and the $\operatorname{tax} \tau=\left(1-P\left(\lambda^{e}\right)\right)\left[\left(1-\lambda^{e}\right) \bar{e}\left(\lambda^{e}\right) r_{p}+\lambda^{e} r_{d}\right]$ is computed ex-ante based on rational expectations, so that the expected net outlays of the DIS are fully funded by banks.

${ }^{23}$ The arbitrage condition (12) can be written as:

where (using $e_{c}<e^{m}$ ):

$$
\frac{r_{p}}{r_{d}}=\frac{1-\int_{0}^{e_{c}}(1-\delta(\lambda, e)) f(e) d e}{e^{m}-\int_{0}^{e_{c}}(1-\delta(\lambda, e)) e f(e) d e}=\frac{1}{e^{m}} \times t(\lambda)
$$$$
t(\lambda) \equiv \frac{1-\int_{0}^{e_{c}}(1-\delta(\lambda, e)) f(e) d e}{1-\int_{0}^{e_{c}}(1-\delta(\lambda, e)) \frac{e}{e^{m}} f(e) d e}<1 .
$$ 


$$
\frac{r_{p}}{r_{d}}<\frac{1}{e^{m}}
$$

suggests that, for any given pair of deposit rates:

$$
\operatorname{Pr}_{d}\left(\bar{e} \frac{r_{p}}{r_{d}}-1\right)<\operatorname{Pr}_{d}\left(\frac{\bar{e}}{e^{m}}-1\right)
$$

However, $r_{d}^{D I S}=r_{f}<r_{d}$ and $\bar{e}^{D I S}<\bar{e}$ imply that we cannot rule out cases in which the marginal impact on current revenues from increasing the dollarization ratio under deposit insurance is smaller than without insurance, that is, $\pi^{\prime D I S}<\pi^{\prime}$.

This ambiguity reflects that fact that the endogenous incentive to dollarize comes from the way in which the bank is liquidated and, thus, increases with the probability of default, which deposit insurance, through its effect on bank fundings costs, tends to reduce.

\section{B. Bank insurance}

In the absence of deposit insurance, a lender of last resort (LLR) policy (or any other bank insurance policy that reduces the incidence of large devaluations on bank failures) has the same effect as a DIS inasmuch as it enlarges the range of end-of-period exchange rates over which dollar depositors are insulated from exchange rate risk. ${ }^{24}$ However, as opposed to deposit insurance, inasmuch as it preserves the claim of shareholders on the bank charter, the LLR introduces a new incentive to dollarize above and beyond the level encouraged by the effects cited above. To distinguish between these two different channels, we assume in what follows that depositors are already covered by a full DIS.

A currency-blind LLR policy that we have in mind is the following: whenever the exchange rate at the end of the period falls below $e_{c}$, with a probability $\beta$ the central bank covers the gap between bank assets and liabilities at no cost. The bank's probability of survival is then given by

$$
b(\lambda)=(1-\beta) P(\lambda)+\beta,
$$

\footnotetext{
${ }^{24}$ We deliberately ignored the delicate question of whether institutions are solvent or iliquid in the event of a large devaluation (related, among other things, to the perceived temporariness of the exchange rate adjustment), and whether indeed a LLR should assist banks in those circumstances.
} 
where $b(\lambda)>P(\lambda)$ and $0>b^{\prime}(\lambda)=(1-\beta) P^{\prime}(\lambda)>P^{\prime}(\lambda)$. The bank's problem then becomes:

$$
V_{L L R}=\max _{\lambda} \frac{\pi(\lambda)}{1-\rho b(\lambda)}
$$

Proposition 4. Under a blanket LLR policy, the equilibrium level of dollarization is weakly higher than otherwise,

$$
\lambda^{L L R} \geq \lambda^{D}
$$

Proof. From the first order condition

$$
\frac{\partial V_{L L R}}{\partial \lambda}=\frac{1}{1-\rho b(\lambda)}\left(\pi^{\prime}+\rho b^{\prime} V_{L L R}\right)=0
$$

it follows that a sufficient condition for $\lambda^{L L R} \geq \lambda^{D}$ is $b^{\prime} V_{L L R} \geq P^{\prime} V$. But

$$
b^{\prime} V_{L L R}=(1-\beta) P^{\prime} V \frac{1-\rho P(\lambda)}{1-\rho b(\lambda)} \geq P^{\prime} V
$$

since $P^{\prime}<0$ and

$$
\begin{aligned}
(1-\rho b(\lambda)) & =1-\rho P(\lambda)-\rho \beta(1-P(\lambda)) \\
& \geq 1-\rho P(\lambda)-\beta(1-\rho P(\lambda)) \\
& =(1-\beta)(1-\rho P(\lambda))
\end{aligned}
$$

Thus, an LLR policy results in a reduction in the cost of risk to the banks (ie., the loss of future rents) which induces risk-taking behavior. In the context of our model, this behavior implies engaging in additional dollar funding. It should be clear to the reader that these results rely on the (quite realistic) assumption that the LLR facility is available to banks irrespective of their dollarization ratio which means that the chances of preserving the insurance benefits in the event of a devaluation are enhanced without any increase in the effective cost of dollar funding to the bank. In other words, the bank benefits from lower 
dollar rates, transferring the cost to the LLR. ${ }^{25}$

Proposition 4 is analogous to results in Kareken and Wallace (1978) and Burnside et al. (2001). Dollarization here arises due to the standard moral hazard consequences of insurance. However, the nature of the government guarantee is different in our paper, as the result does not hinge on the existence of bankruptcy costs as in the aforementioned papers. Furthermore, in this paper, the banks' portfolio decisions are related to the currency composition of their liabilities rather than that of their assets.

From a normative standpoint, it is easy to conceive an LLR rule contingent on the degree of dollarization of the bank, such that $\beta(\lambda), \beta^{\prime}(\lambda)<0$, which can readily undo the distortion associated with the insurance policy. In this case,

$$
b^{\prime}(\lambda)=(1-\beta) P^{\prime}+(1-P) \beta^{\prime}
$$

which can be set to the desired level of dollarization by making $\beta(\lambda)$ arbitrarily steeper.

\section{Bank insurance (Exchange Rate Defense)}

It has been pointed out in the literature that, out of concerns regarding the negative effects of a sharp devaluation on banks' balance sheets, the government may (explicitly or implicitly) intervene in the exchange rate market to limit extreme exchange rate fluctuations. By reducing exchange rate volatility, the government is reducing exchange rate risk faced by the bank (at the expense of the stock of international reserves), which should foster financial dollarization in the same way as in the previous case. ${ }^{26}$ However, in practice there is always a limit to what a government can do to countervail shifts in the equilibrium exchange rate.

We can illustrate this point in the context of our model. Assume that the central bank is expected to intervene in the foreign exchange market to prevent the value of $e$ from falling below $e_{c}$. However, given the limited stock of reserves, for equilibrium exchange rates below a threshold $0 \leq l<e_{c}$, the intervention is expected to fail. Thus, the government effectively modifies the exchange rate distribution faced by banks and depositors so that its support is

\footnotetext{
${ }^{25}$ Again, the results remain true even if the LLR facility is fully funded through a fixed tax on bank profits determined ex-ante.

${ }^{26}$ In different contexts, this point has been raised by Mishkin (1996) and Obstfeld (1998).
} 
now $\left[l, e_{c}\right) \cup\left[e_{c}, \infty\right]$.

An exchange rate defense policy has ambiguous effects on the equilibrium level of dollarization. Two effects offsetting effects of this policy can be identified. First, the exchange rate risk incurred by the bank for a given dollarization ratio is now smaller, as the set of states in which a bank defaults narrows. More precisely, the bank now avoids default with a probability

$$
P^{E R D}(\lambda)=\int_{e_{c}(\lambda)}^{\infty} f(e) d e+\int_{l}^{e_{c}(\lambda)} f(e) d e=P(\lambda)+i(\lambda) \geq P(\lambda)
$$

with an effect similar to that of the lender of last resort studied previously. As in Dooley (1997) this policy acts as a bank insurance for banks and increases their incentive to dollarize at the expense of Central Bank reserves. However, this policy also reduces the probability of default (by lowering $e_{c}$ to $l$ ) which in turn reduces the expected cross transfer $s(\lambda)$ for any given pair of deposit rates (see equation (10), (10) and Remark 1). Trivially, for $l=0$, $s(\lambda)=0$ and, in equilibrium, $\lambda^{E R D}=0$. Moreover, the intervention policy also changes the exchange rate distribution faced by depositors. By shifting the distribution to the right, it increases the preference for peso deposits and narrows the peso-dollar spread, again detracting from the cross-transfer and the incentives for dollar funding. Thus, the impact of expected exchange rate intervention is ambiguous. ${ }^{27}$

\section{Numerical simulations}

In this section we provide a simulation of the model presented in section 2 to provide additional insight into the analytical results. For this purpose, we use the following Gamma distribution for the end-of-period exchange rate:

$$
f(e)=\frac{e}{\Gamma(2)\left(\frac{2}{5}\right)^{2}} \exp \left(-\frac{5}{2} e\right) d e, \quad 0 \leq e<\infty
$$

\footnotetext{
${ }^{27} \mathrm{~A}$ different case arises if the government is expected to bail out banks in the event of a large depreciation without intervening in the exchange rate market, for example through the extension of subsidized liquidity assistance. Trivially, if part of the exchange rate risk is directly borne by the government, banks will face stronger incentives to fund themselves in dollars.
} 
where $\Gamma(n)=(n-1)$ !. This distribution implies that $e^{m}=0.9$. That is, given that $e_{0}=1$, the expected depreciation of the currency equals 11.1 percent. $^{28}$ It is further assumed that depositors are covered by partial deposit insurance up to a fraction $\delta^{D I S}=\max \{\delta(\lambda, e), k\}$, where $k=0.7$. Parameter values appear in the notes to the first figure. In particular, note that the choice of parameters satisfy the condition of Proposition $3\left(\rho<\rho^{c}\right)$, so that the decentralized equilibrium implies a positive level of dollarization.

Figure 1 presents the static profit function in (2) for a given expected dollarization ratio, $\lambda^{e}=0$, and the value functions in (9) for $\lambda^{e}=0$ and $\lambda^{e}=1$. This discount factor assumed is discount factor $\rho=0.4$ (note that $\rho<\rho_{c}$ ). As shown in the previous section, the static profits are increasing in $\lambda$ for all $\lambda$. However, an increase in $\lambda$ also generates an increased probability of default in the future and thus reduces intertemporal profits. Figure 1 shows that for low levels of $\lambda$ the intertemporal loss more than compensates for the gains in current profits. This effect gives the value function a U-shape. From the value functions presented in Figure 1 it is clear that $\lambda=0$ is not an equilibrium and that $\lambda=1$ is an equilibrium. ${ }^{29}$ It is easy to show that that $\lambda=1$ is the unique equilibrium of this game. For the comparative statics that follow we adopt the case where $\rho=0.4$ and $\lambda^{e}=1$ as our baseline simulation.

Key to the main results of the paper is the fact that a bank will default in states of nature in which the local currency suffers a significant depreciation (i.e., the exchange rate falls below a critical threshold $e_{c}$ ). Figure 2 shows the evolution of $e_{c}, \bar{e}$ (the average exchange rate conditional on no default), and $P$, the probability of survival, as $\lambda$ increases. At $\lambda=0$, both the threshold $e_{c}$ and the probability of default, $(1-P)$, are zero, and the conditional and unconditional expected exchange rate coincide $\left(\bar{e}=e^{m}=0.9\right)$. As $\lambda$ increases, $e_{c}$ goes up, as bank liabilities (which are now partially denominated in dollars) exceed bank assets (which are peso-denominated) for very low values of $e$. This implies that for $\lambda>0$, the probability of default is higher than zero $(1-P>0)$, and the conditional mean increases beyond the unconditional mean, i.e., $\bar{e}>e^{m}$.

As defaults are associated with low values of the exchange rate (see Figure 2), a currency-

\footnotetext{
${ }^{28}$ The choice of $e^{m}<1$ is purely for expositional purposes. From the previous discussion, it follows that any Gamma distribution with $f(0)=0$ and domain in $R^{+}$would yield identical qualitative results.

${ }^{29}$ It is immediate to see that $V\left(\lambda^{e}=0, \lambda=0\right)<V\left(\lambda^{e}=0, \lambda=1\right)$, which rules out an equilibrium at $\lambda=0$, and that $V\left(\lambda^{e}=1, \lambda=1\right)>V\left(\lambda^{e}=1, \lambda\right)$ for all $\lambda \epsilon[0,1)$.
} 
blind liquidation policy implies that dollar returns are higher than peso returns in those states. Arbitrage requires that these higher returns be compensated by lower returns in non-default states, which, in turn, implies lower relative effective cost of dollar funding to banks by a factor proportional to $s(\lambda)$. Figure 3 shows how the relative cost of peso funding increases with $\lambda$. As noted, for $\lambda=0$, the bank never defaults and the relative cost is simply one. However, as $\lambda$ increases, so do the probability of default and the conditional expected exchange rate (so that banks pay only in the case of small depreciations), raising the relative effective cost of peso funding.

Proposition 2 in section 2 shows that there is a critical rho, $\rho_{c}$, such that for all $\rho<\rho_{c}$, the decentralized equilibrium is at $\lambda^{D}>0$, while for $\rho \geq \rho_{c}, \lambda^{D}=0$. Figure 4 plots the value function (evaluated at $\lambda^{e}=0$ ) at different values of $\rho$ for the baseline simulation (where $\left.\rho_{c}=0.887\right)$. Only when $\rho>\rho_{c}$ do we obtain $V\left(\lambda^{e}=1, \lambda=1\right)<V\left(\lambda^{e}=1, \lambda=0\right)$, so that the equilibrium is no longer at $\lambda=1$.

\section{A. Empirical measurement of currency risk}

Currency risk is typically (albeit incorrectly) used to denote both the currency risk premium as directly measured from differential returns on assets denominated in local and foreign currencies, and exchange rate (devaluation) expectations. An important, and often overlooked, consequence of this is the fact that the peso-dollar premium as measured from the market rates of return in each currency, is not independent from either the financial dollarization ratio or the existence of deposit or bank insurance. ${ }^{30}$ More concretely, as indicated in (21), inasmuch as there is some uninsured risk of default, the measured currency risk $\left(\frac{r_{p}}{r_{d}}\right)$ underestimates the true currency risk $\left(\frac{1}{e^{m}}\right) \cdot{ }^{31}$

Figure 5 illustrates this finding using the parameters of our baseline simulation. In full dollarization case, even though the true currency risk is 11.1 percent, the measured currency

\footnotetext{
${ }^{30}$ There are other asset-specific factors that may influence the currency risk premium, such as counterparty risk. See Schmukler and Serven (2001).

${ }^{31}$ This mismeasurement is itself correlated, among other things, with the true level of currency risk and with liquidation costs. Indeed, it is easy to check that the higher the liquidation cost (the smaller $\theta$ ), the smaller the peso-dollar spread and the higher its difference with the true currency risk. Trivially, as liquidation costs increase (and the recovery value of deposits with a failed bank falls to zero), the peso-dollar spread converges to the effective relative funding cost, $\frac{1}{\bar{e}}$.
} 
risk is only 8.5 percent. Note that, as the dollarization ratio approaches zero (and default risk disappears), the interest rate spread converges to the true currency risk.

The appendix shows a formal proof that this difference between the true currency risk

$\left(\frac{1}{e^{m}}\right)$ and the measured currency risk $\left(\frac{r_{p}}{r_{d}}\right)$ is higher for high levels of dollarization. The intuition behind the result is the following. As dollarization increases, both the recovery rate and the range of exchange rate outcomes for which exchange rate risk is perfectly insured by dollar deposits decline, making dollar deposits relatively less attractive. Conversely, the peso-dollar spread declines as we approach zero dollarization, converging to the true currency risk in the limit.

\section{Conclusions}

This paper developed a simple framework to understand the interaction between depositors, banks and the central bank in a bi-currency banking sector with exchange rate risk. It departed from the traditional model of Kareken and Wallace (1978) in that banks choose the currency composition of their deposit portfolio for a given asset structure.

We found, in general, that equal treatment of peso and dollar claims in the event of a bank default, by raising the peso-dollar interest rate spread above the effective relative funding costs faced by banks, generates an incentive to dollarize deposits. The results obtained link the characteristics of the banking safety net scheme (loss-sharing policy, deposit and bank insurance) with the currency composition of deposits. When safety nets do not discriminate between currencies, part of the exchange rate insurance of dollar deposits is extended to the default scenario at the expense of peso depositors or the government. Risk neutral depositors price this extra benefit of dollar deposits into lower dollar rates relative to peso rates. Banks, however, do not pay the higher costs of dollar deposits in the event of default and thus find it cheaper to finance their projects through dollar funding.

This result differs from results in related literature in two important ways. First, the incentive to dollarize is present even in the absence of government or private exchange rate guarantees. We show that, under quite general conditions, any bank liquidation policy that recognizes the currency of denomination of outstanding liabilities induces financial dollarization that is unwarranted (dollarization that would not arise in the model if dollar-funded 
banks were forced to separate from peso funded banks) and excessive (in the model, dollarization is suboptimal from a central planner's point of view). Second, we find that a currency-blind deposit insurance creates incentives to dollarize that arise from its effect on the pricing of deposits rather than from the well-known moral hazard consequences of insurance. Moral hazard does play a role in the case of bank insurance (lender of last resort) that lead banks to increase the level of deposit dollarization, since part of the cost of this action is transferred to the provider of the insurance services. As such, our findings provide an alternative explanation for the much discussed issue of the prevalent use of the foreign currency in financial intermediation in most bi-monetary economies.

Natural extensions of the present model would introduce non-exchange rate related risk (from which we deliberately abstracted), and would endogenize the exchange rate (to reflect the incidence of balance sheet costs in the government reaction to sudden adverse exchange rate shocks). Regarding the former, our conjecture is that, inasmuch as the capacity of banks (or, more generally, of dollar debtors) to pay is strongly correlated with the exchange rate, the qualitative results should remain. As for the latter, if the anticipation of an exchange rate defense favors deposit dollarization, then higher dollarization ratios, associated with higher balance sheet costs, should make the defense ever more likely, reinforcing the effects described in this paper. Both issues deserve a more careful (analytical and empirical) exploration.

The model could also be extended in two additional dimensions. On the one hand, while our focus on banks allowed us to study the influence of deposit insurance and central bank assistance on dollarization, it follows closely that, by substituting firms for banks, the main result, namely that currency-blind liquidation fosters dollar funding, could be readily applied to direct financing. In a more interesting extension, the intuition developed here could also be used to explain the tendency of both the private and public sectors in most developing countries to seek finance abroad in foreign currencies. In the presence of a non-neglegible probability of default, foreign investors, anticipating an equal treatment across currencies in the event of default, would demand local currency premiums deemed excessive by local borrowers, thus inducing the dollarization of external debt.

The driving force behind the endogenous dollarization described in this paper is the equal treatment of peso and dollar deposits in the event of a bank default despite the fact that 
dollar deposits are the source of risk. As noted, this treatment is not unusual in practice. Bankruptcy laws do not adjust creditors' assets for their currency of denomination. Similarly, deposit insurance schemes tend to cover both local and foreign currency deposits in the same terms. The case of a lender of last resort is even clearer, since central banks are not known to base their assistance to particular banks on the currency composition of their portfolios above and beyond what it is required by prudential regulations. Thus, on the positive front, this paper highlights the challenges that a bi-currency financial sector raises for the standard currency-blind nature of banking practices which are typically conceived with single-currency developed economies in mind. The negative externalities associated with deposit dollarization (due to the presence of liquidation costs) are no different than those associated with excessive bank risk-taking of any kind, and should be treated with similar concern by the regulator. 


\section{References}

[1] Allen, F. and D. Gale, 1998, Optimal Banking Crises, Journal of Finance 4 (53), 1245-84.

[2] Balino, T., A. Bennett and E. Borensztein, 1999, Monetary Policy in Dollarized Economies, Occasional Paper No. 171.

[3] Blum, J., 1999, Do Capital Adequatcy Requirements reduce risk in banking?, Journal of Banking $\& 3$ Finance 23, 755-771.

[4] Burnside, Craig, Martin Eichenbaum, Sergio Rebelo, 2001, Hedging and Financial Fragility in Fixed Exchange Rate Regimes, European Economic Review 45 (7), 115193.

[5] Burnside, Craig, Martin Eichenbaum, Sergio Rebelo, 2001b, Prospective Deficits and the Asian Currency Crisis, Journal of Political Economy 109 (6), 1155-97.

[6] Caballero, R. and A. Krishnamurthy, 2002, Excessive Dollar Debt, forthcoming Journal of Finance.

[7] Demirguc-Kunt, Asli; Detragiache, Enrica, 2000, Monitoring Banking Sector Fragility: A Multivariate Logit Approach, World Bank Economic Review 14 (2), 287-307

[8] Diaz-Alejandro, Carlos, 1985, Goodbye Financial Repression, Hello Finanical Crash, Journal of Development Economics, 19:1-4.

[9] Dooley, Michael P., 1997, A Model of Crises in Emerging Markets, National Bureau of Economic Research Working Paper: 6300, 27.

[10] Freixas and Rochet, 1997, Microeconomics of Banking, MIT Press.

[11] Garcia, Gillian, 1999, Deposit Insurance - A Survey of Actual and Best Practices, IMF $\mathrm{WP} / 99 / 54$.

[12] Girton, L. and D. Roper, 1981, Theory and Implications of Currency Substitution, Journal of Money, Credit and Banking 13, 12-30. 
[13] Guidotti, P. and C.Rodriguez, 1992, Dollarization in Latin America: Gresham's Law in Reverse?, IMF Staff Papers, Washington: IMF, v.38, 518-544.

[14] Kareken, J. and N.Wallace, 1978, Deposit Insurance and Bank Regulation: A Partial Equillibrium Exposition, Journal of Business 51,413-438.

[15] Kyei, A., 1995, Deposit Protection Arrangements: A Survey, IMF WP95/134.

[16] Ize, A. and E.Levy-Yeyati, 2001, Financial Intermediation, forthcoming, Journal of International Economics.

[17] McNellis, P. and L. Rojas-Suárez, 1996, Exchange-Rate Depreciation, Dollarization and Uncertainty: A Comparison of Bolivia and Peru, Inter-American Development Bank WP-325.

[18] Modigliani, F. and H. Miller, 1958, The cost of capital, corporation finance and the theory of investment, American Economic Review 48 (3), 261-97.

[19] Obstfeld, M., 1998, "The Global Capital Market: Benefactor or Menace?," Journal of Economic Perspectives 12, 9-30.

[20] Sahay, R.and C.Vegh, 1995, "Dollarization in Transition Economies: Evidence and Policy Implications," IMF WP/95/96.

[21] Schmukler, S. and Serven, L., 2002, Pricing Currency Risk: Facts and Puzzles from Currency Boards, World Bank Policy Research Working Paper 2815.

[22] Suarez, J., 1993, "Closure rules, market power and risk-taking in a dynamic model of bank behavior," Discussion paper, Universidad Carlos III, Madrid.

[23] Sturzenegger, F., 1992, "Currency Substitution in Developing Countries: An Introduction," Revista de Analisis Economico 7, 3-28.

[24] Thomas, L., 1985, "Portfolio Theory and Currency Substitution," Journal of Money, Credit and Banking17, 347-357.

[25] Uribe, M., 1997, "Hysterisis in a simple model of Currency Substitution," Journal of Monetary Economics 40,185-202. 


\section{Appendix}

\section{.1. Useful properties}

$$
\begin{array}{cc}
e_{c}^{\prime}(\lambda)=\frac{r_{d}\left(R-r_{p}\right)}{\left[R-(1-\lambda) r_{p}\right]^{2}}=\frac{\left(R-r_{p}\right)}{R-(1-\lambda) r_{p}} \frac{e_{c}}{\lambda}>0 & \bar{e}^{\prime}=-\frac{e_{c}^{\prime}(\lambda) f\left(e_{c}\right) e_{c}}{P}-\frac{P^{\prime} \bar{e}}{P}=\frac{P^{\prime}}{P}\left(e_{c}-\bar{e}\right)>0 \\
e_{c}^{\prime \prime}(\lambda)=-\frac{r_{d} r_{p}\left(R-r_{p}\right)}{\left[R-(1-\lambda) r_{p}\right]^{3}}=-\frac{e_{c}^{\prime}(\lambda) r_{p}}{R-(1-\lambda) r_{p}}<0 & P^{\prime}(\lambda)=-e_{c}^{\prime}(\lambda) f\left(e_{c}\right)<0 \\
\frac{e_{c}^{\prime}}{e_{c}}=\frac{\left(R-r_{p}\right)}{R-(1-\lambda) r_{p}} \frac{1}{\lambda} & P^{\prime \prime}(\lambda)=-e_{c}^{\prime \prime}(\lambda) f\left(e_{c}\right)-\left[e_{c}^{\prime}(\lambda)\right]^{2} f^{\prime}\left(e_{c}\right) \gtreqless 0
\end{array}
$$

\section{.2. Proof of Proposition 1:}

First note that, using (17) and (18), we know that, at $\lambda=0, s(0)=1 \Rightarrow \pi^{\prime}(0)=0$, $e_{c}(0)=0 \Rightarrow P^{\prime}(0)=0 \Rightarrow \pi^{\prime \prime}(0)=0$ and $P^{\prime \prime}(0)<0$ so that, from

$$
\pi^{\prime \prime \prime}=P^{\prime \prime}\left(e_{c} r_{p}-r_{d}\right)-P^{\prime}\left(e_{c}^{\prime} r_{p}\right) \geq 0
$$

we know that

$$
\pi^{\prime \prime \prime}(0)=-P^{\prime \prime}(0) r_{f}>0
$$

This, combined with the fact that, for $\lambda>0, s(\lambda)>0 \Rightarrow \pi^{\prime}(\lambda)>0$, implies that the equilibrium for $\rho=0$ (alt., for the static problem) is at $\lambda=1$.

To show that $\lambda=0$ is not an equilibrium, it suffices to show that, for $\rho \in\left(0, \rho^{c}\right]$, there is some feasible $\tilde{\lambda} \in(0,1]$ such that $V\left(\lambda^{e}=0, \lambda=0\right)<V\left(\lambda^{e}=0, \lambda=\tilde{\lambda}\right)$. In particular, we do that for $\tilde{\lambda}=1$. Denoting $f_{\lambda}=f\left(\lambda^{e}=0, \lambda\right)$ to simplify notation, we obtain:

$$
V_{0}=\frac{e^{m} R-r_{f}}{1-\rho}<\frac{P_{1}\left(\bar{e}_{1} R-r_{f}\right)}{1-\rho P_{1}}=V_{1}
$$

iff

$$
\rho P_{1}\left(\bar{e}_{1}-\underline{e}_{1}\right) R<r_{f}-\underline{e}_{1} R
$$

for which

$$
\rho \leq \frac{r_{f}}{e^{m} R}
$$

is a a sufficient condition. 


\section{.3. Section 4. Proof of $\frac{d t}{d \lambda}<0$}

To see this, first note that, from (14), we know that the maximal recovery rate $\delta(\lambda, e)<\theta$.

In turn, using $P^{\prime}<0$,

$$
\delta_{1}(\lambda, e)^{\prime}=e \theta R \frac{e r_{p}-r_{d}-e(1-\lambda) r_{p}^{\prime}-\lambda r_{d}^{\prime}}{\left[e(1-\lambda) r_{p}+\lambda r_{d}\right]^{2}}<0
$$

Finally, using (4.1), $\frac{d t}{d \lambda}<0$ follows from :

$$
\begin{aligned}
& {\left[1-\int_{0}^{e_{c}}[1-\delta(\lambda, e)] \frac{e}{e^{m}} f(e) d e\right]\left[e_{c}^{\prime}\left[1-\delta\left(\lambda, e_{c}\right)\right] f\left(e_{c}\right)-\int_{0}^{e_{c}} \delta_{1}(\lambda, e)^{\prime} f(e) d e\right] } \\
> & \frac{e_{c}}{e^{m}}\left[1-\int_{0}^{e_{c}}[1-\delta(\lambda, e)] f(e) d e\right]\left[e_{c}^{\prime}\left[1-\delta\left(\lambda, e_{c}\right)\right] f\left(e_{c}\right)-\int_{0}^{e_{c}} \delta(\lambda, e)^{\prime} \frac{e}{e_{c}} f(e) d e\right]
\end{aligned}
$$


Figure 1

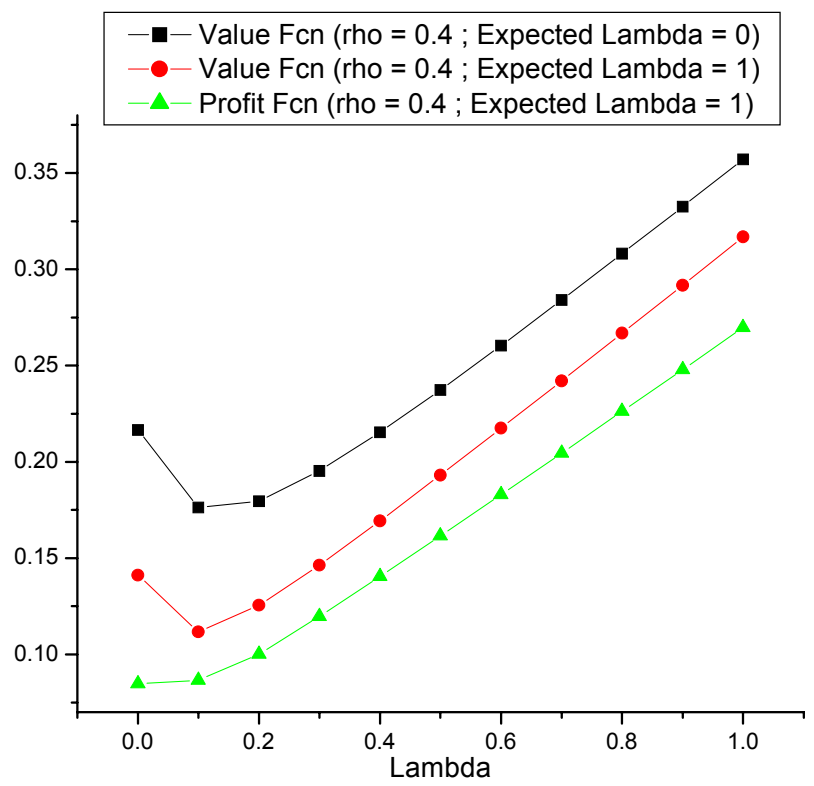

Notes: The exogenous parameters used are the following : $\mathrm{rf}=1.04 ; \mathrm{R}=1.2$; $d=0.8$; the distribution for the exchange rate used is given by $(x x)$ in the main text.

Figure 2

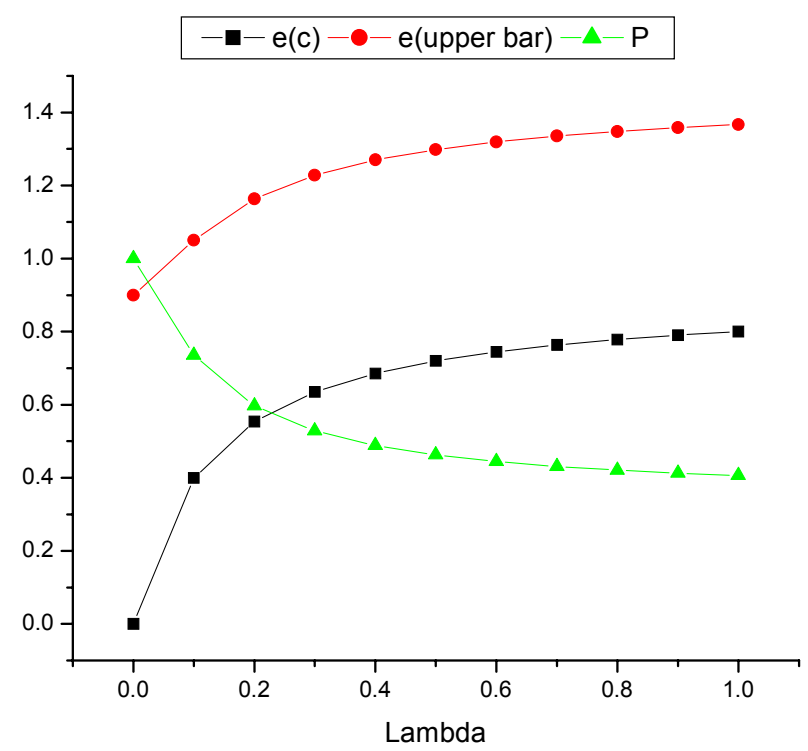

Notes: Same Notes as if Figure 1. 
Figure 3

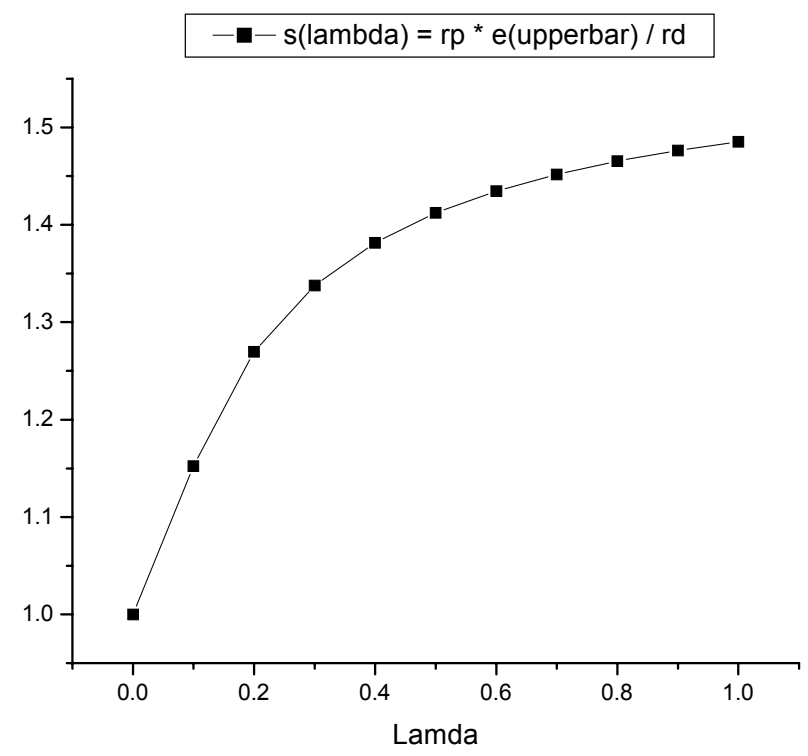

Notes: This figure shows the effective cost of peso deposits relative to dollar deposits for banks (i.e., rp*e(upperbar)/rd).

Figure 4

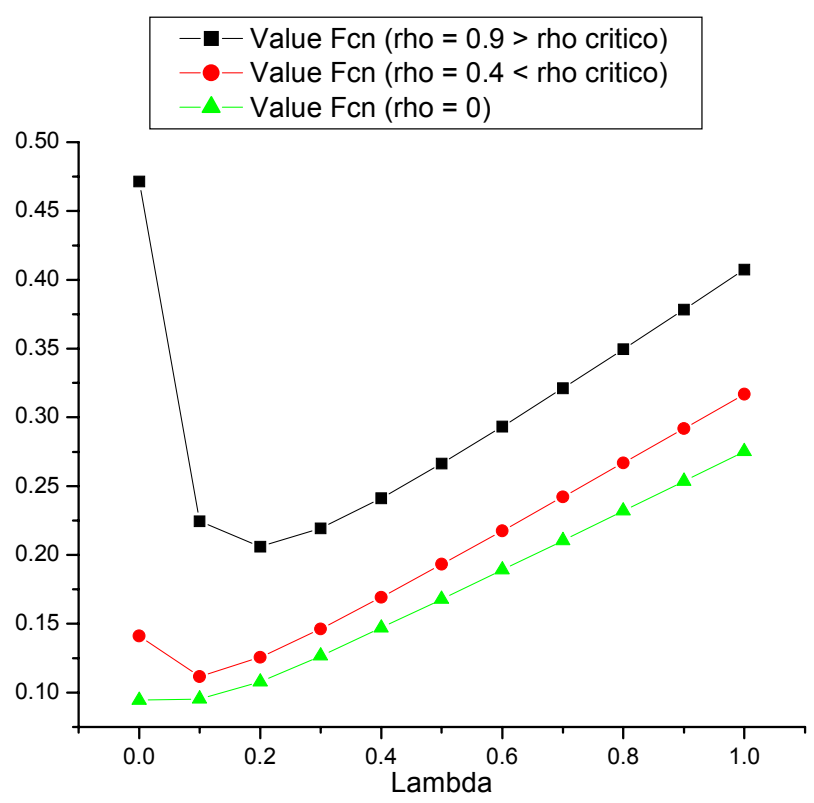

Notes: This figure shows that as rho falls it is more probable that lambda $=1$ is an equilibrium. 
Figure 5

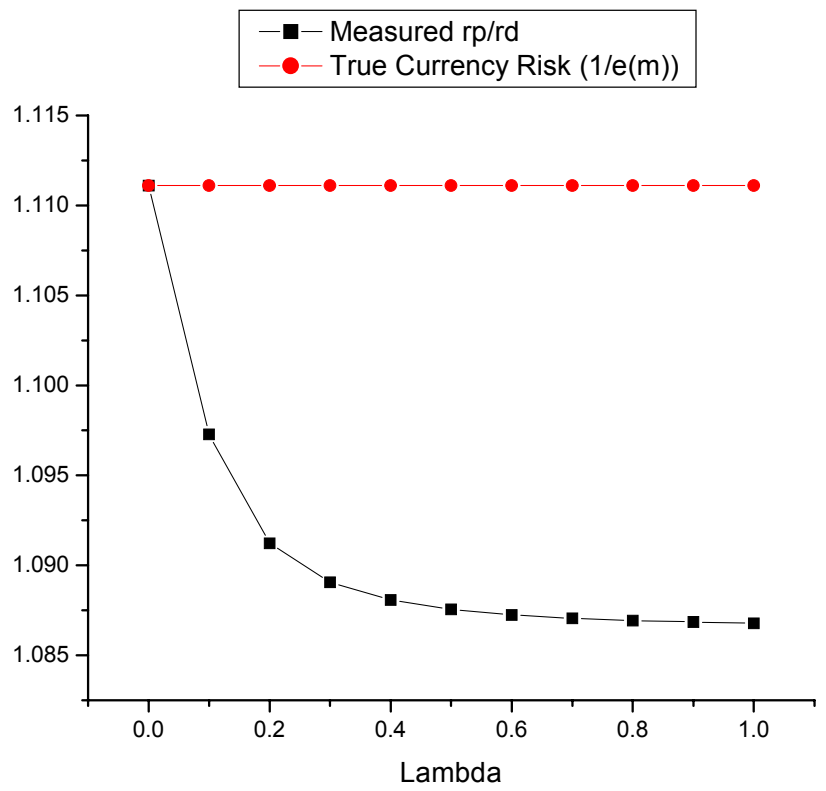




\section{Universidad Torcuato Di Tella, Business School Working Papers}

\section{Working Papers 2003}

NN16 "Business Cycle and Macroeconomic Policy Coordination in MERCOSUR"

Martín Gonzalez Rozada (UTDT) y José Fanelli (CEDES).

No15 "The Fiscal Spending Gap and the Procyclicality of Public Expenditure"

Eduardo Levy Yeyati (UTDT) y Sebastián Galiani (UDESA).

No14 "Financial Dollarization and Debt Deflation under a Currency Board"

Eduardo Levy Yeyati (UTDT), Ernesto Schargrodsky (UTDT) y Sebastián Galiani (UDESA).

№13 " ¿ Por qué crecen menos los regímenes de tipo de cambio fijo? El efecto de los Sudden Stops", Federico Stuzenegger (UTDT).

№12 "Concentration and Foreign Penetration in Latin American Banking Sectors: Impact on Competition and Risk", Eduardo Levy Yeyati (UTDT) y Alejandro Micco (IADB).

№11 "Default 's in the 1990's: What have we learned?",

Federico Sturzenegger (UTDT) y Punan Chuham (WB).

№10 "Un año de medición del Indice de Demanda Laboral: situación actual y perspectivas",

Victoria Lamdany (UTDT) y Luciana Monteverde (UTDT)

N'09 "Liquidity Protection versus Moral Hazard: The Role of the IMF",

Andrew Powell (UTDT) y Leandro Arozamena (UTDT)

№8 "Financial Dedollarization: A Carrot and Stick Approach", Eduardo Levy Yeyati (UTDT)

No07 "The Price of Inconvertible Deposits: The Stock Market Boom during the Argentine crisis",

Eduardo Levy Yeyati (UTDT), Sergio Schmukler (WB) y Neeltje van Horen (WB)

NN06 "Aftermaths of Current Account Crisis: Export Growth or Import Contraction?",

Federico Sturzenegger (UTDT), Pablo Guidotti (UTDT) y Agustín Villar (BIS)

No5 "Regional Integration and the Location of FDI",

Eduardo Levy Yeyati (UTDT), Christian Daude (UM ) y Ernesto Stein (BID)

N04 "A new test for the success of inflation targeting",

Andrew Powell (UTDT), Martin Gonzalez Rozada (UTDT) y Verónica Cohen Sabbán (BCRA)

No03 "Living and Dying with Hard Pegs: The Rise and Fall of Argentina's Currency Board",

Eduardo Levy Yeyati (UTDT), Augusto de la Torre (WB) y Sergio Schmukler (WB)

No02 "The Cyclical Nature of FDI flows",

Eduardo Levy Yeyati (UTDT), Ugo Panizza (BID) y Ernesto Stein (BID) 
№1 "Endogenous Deposit Dollarization",

Eduardo Levy Yeyati (UTDT) y Christian Broda (FRBNY)

\section{Working Papers 2002}

№15 "The FTAA and the Location of FDI",

Eduardo Levy Yeyati (UTDT), Christian Daude (UM ) y Ernesto Stein ( BID)

No14 "Macroeconomic Coordination and Monetary Unions in a N-country World: Do all Roads

Lead to Rome?"

Federico Sturzenegger (UTDT) y Andrew Powell (UTDT)

№13 "Reforming Capital Requirements in Emerging Countries"

Andrew Powell (UTDT), Verónica Balzarotti (BCRA) y Christian Castro (UPF)

№12 "Toolkit for the Analysis of Debt Problems", Federico Sturzenegger (UTDT)

№11 "On the Endogeneity of Exchange Rate Regimes",

Eduardo Levy Yeyati (UTDT), Federico Sturzenegger (UTDT) e lliana Reggio (UCLA)

№10 "Defaults in the 90's: Factbook and Preliminary Lessons", Federico Sturzenegger (UTDT)

No09 "Countries with international payments ' difficulties: what can the IMF do?"

Andrew Powell (UTDT)

NN08 "The Argentina Crisis: Bad Luck, Bad Management, Bad Politics, Bad Advice",

Andrew Powell (UTDT)

N07 "Capital Inflows and Capital Outflows: Measurement, Determinants, Consequences",

Andrew Powell (UTDT), Dilip Ratha (WB) y Sanket Mohapatra (CU)

No06 "Banking on Foreigners: The Behaviour of International Bank Lending to Latin America, 1985-2000",

Andrew Powell (UTDT), María Soledad Martinez Peria (WB) y Ivanna Vladkova ( IMF)

No05 "Classifying Exchange Rate Regimes: Deeds vs. Words"

Eduardo Levy Yeyati (UTDT) y Federico Sturzenegger (UTDT)

NN04 "The Effect of Product Market Competition on Capital Structure: Empirical Evidence from the

Newspaper Industry", Ernesto Schargrodsky (UTDT)

N03 "Financial globalization: Unequal blessings",

Augusto de la Torre (World Bank), Eduardo Levy Yeyati (Universidad Torcuato Di Tella) y Sergio

L. Schmukler (World Bank)

N02 "Inference and estimation in small sample dynamic panel data models",

Sebastian Galiani (UdeSA) y Martin Gonzalez-Rozada (UTDT)

№1 "Why have poverty and income inequality increased so much? Argentina 1991-2002",

Martín González-Rozada, (UTDT) y Alicia Menendez, (Princeton University). 